\title{
A specific ELISA for measuring neurofilament heavy chain phosphoforms
}

\author{
A. Petzold * G. Keir A.J.E. Green G. Giovannoni \\ E.J. Thompson \\ Department of Neuroimmunology, Institute of Neurology, University College \\ London, Queen Square, London WC1N 3BG, United Kingdom
}

\begin{abstract}
Neurofilaments (Nf) are the major constitutents of the axoskeleton and body fluid $\mathrm{Nf}$ levels are an important tool for estimating axonal degeneration in vivo. This paper presents a new sandwich ELISA allowing quantification of the $\mathrm{NfH}^{\text {SMI35 }}$ phosphoform from CSF, brain tissue and cell-culture homogenates. The sensitivity of the

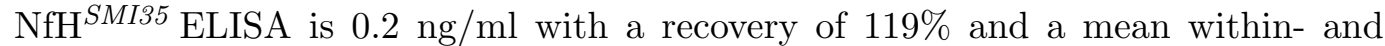
between-batch precision of $10.6 \%$ and $23 \%$, respectively. CSF $\mathrm{NfH}^{S M I 35}$ was stable at $4^{\circ} \mathrm{C}$, not influenced by freeze-thaw cycles, and proteolysis present at room temperature could be prevented by adding protease inhibitors. Aggregate formation was observed for HPLC-purified bovine $\mathrm{NfH}$ and could be resolved by sonication.

The upper reference value for CSF $\mathrm{NfH}^{\text {SMI35 }}$ levels $(0.73 \mathrm{ng} / \mathrm{ml})$ was defined as the $95 \%$ cumulative frequency from 416 CSF samples. Based on this cut-off a significantly higher proportion of patients with amyotrophic lateral sclerosis, spaceoccupying lesions, disc prolapse and subarachnoid haemorrhage had pathologically elevated $\mathrm{NfH}^{\text {SMI35 }}$ levels compared to patients with cluster headache or demyelinating disease.
\end{abstract}

A new nomenclature is proposed in order to facilitate the comparison between ELISA, immunoblotting and immunocytochemistry.

Key words: neurofilament, nfh, nomenclature, ELISA, CSF, neurodegeneration, axonal injury, smi34, smi35, smi310, smi32, smi33, smi37, smi38, smi311, ne14

\footnotetext{
* Dr Axel Petzold, Department of Neuroimmunology, Institute of Neurology, Queen Square, London WC1N 3BG, United Kingdom. Tel.: +44 2078373611 ext. 4204, Fax +44 207837 8553, Email: a.petzold@ion.ucl.ac.uk
} 
Neurofilaments (Nf) are the principal component of the axoskeleton and are released during axonal damage. Body fluid levels of Nf are important candidates for validation as surrogate markers for axonal degeneration in neurological disorders. At present there are no commercial ELISA kits available for the quantification of any of the three Nf subunits. One group developed a sandwich ELISA technique for the detection of the Nf light chain (NfL) in the cerebrospinal fluid (CSF), based on in-house antibodies Rosengren et al. (1996). Confirmation of the results derived by this group has, however, been hampered by the non-availability of the antibodies. Another group published an ELISA for NfL and two phosphoforms of the Nf heavy chain (NfH) in brain homogenate Hashimoto et al. (1999), but that assay lacked precision.

Nf are obligate heteropolymers composed of 3 subunits (NfL, NfM, NfH) and belong to the class IV-intermediate filaments Fuchs and Cleveland (1998). Nf subunits share an $\alpha$-helical rod domain which is required for the formation of oligomers. It has been suggested that the $\mathrm{N}$-terminal head domain, has regulatory functions of $\mathrm{Nf}$ assembly and that the $\mathrm{C}$-terminal tail domain which is the major site of phosphorylation, plays a role in protein-protein and proteinorganelles interaction Ching and Liem (1998). The length of the C-terminal tail domain differs considerably between the Nf subunits and accounts for the differences in molecular mass. The molecular mass of NfL is $68 \mathrm{kDa}$ and of NfM $160 \mathrm{kDa}$ in SDS gels Fuchs and Cleveland (1998). NfH is encoded on chromosome 22q12.2 and consists of 1020 amino acids Lees et al. (1988), with a molecular mass of $111 \mathrm{kDa}$. Depending on the degree of phosphorylation migration in sodium dodecyl sulfate (SDS) gels is slowed, thus explaining the range of 190 to $210 \mathrm{kDa}$ reported in the literature. The phosphorylated $\mathrm{NfH}$ has proved to be relatively resistant to protease activity Goldstein et al. (1987), whilst NfL is not Schlaepfer et al. (1985); Wang et al. (1992).

The aim of this study was to develop a sandwich ELISA method for the quantification of phosphorylated $\mathrm{NfH}$ in the CSF of neurological patients.

\section{Materials and methods}

\subsection{Antibodies}

Capture (first) antibodies: mouse monoclonal anti-NfH antibodies (SMI clones 32, 33, 34, 35, 37, 38, 310, 311) were purchased from Sternberger Monoclonals (Sternberger Monoclonals Incorporated, Utherville, USA) and Sigma (clone NE14, Sigma, UK). The details of the capture antibodies are summarised in Table 1. The detector (second) antibody: rabbit polyclonal anti-NfH was purchased from Affiniti (Affiniti Research Products, Exeter, UK). The indicator 
(third) horseradish peroxidase (HRP) labelled swine polyclonal anti-rabbit antibody was purchased from DAKO (DAKO, Copenhagen, Denmark).

\subsection{Chemicals}

Sodium barbitone, barbitone, ethylene-diamine-tetra-acetic disodium salt (EDTA), protease inhibitor cocktail (PI, P8340), calcium lactate, 30\% hydrogen peroxide, $\mathrm{NaHCO}_{3}, \mathrm{Na}_{2} \mathrm{CO}_{3}$, Tween 20 and bovine serum albumin (BSA) were of analytical grade (Sigma). TMB was purchased from DAKO. Hydrochloric acid $(\mathrm{HCl})$ was obtained from Merck (Darmstadt, Germany). Bovine HPLC purified GFAP, NfL and NfM were obtained from Affiniti Research Products. NUNC Maxisorb Microtitre plates were obtained from Life Technologies (Paisley, Scotland).

\subsection{Standards}

Bovine NfH was obtained from Affiniti Research Products. Bovine Nf subunits were chosen as the supply of Nf proteins from human brains could not be guaranteed. The standard curve based used for the NfH assay was calculated from dilutions of $50 \mu \mathrm{g}$ HPLC-purified bovine NfH protein in barbitone buffer $(\mathrm{pH} 8.9)$ containing $0.1 \%$ bovine serum albumin, $6 \mathrm{mM}$ EDTA and ranged from 0 to $2 \mathrm{ng} / \mathrm{ml}$. The standards were stored at $-20^{\circ} \mathrm{C}$.

\subsection{CSF samples}

A total of $463 \mathrm{CSF}$ samples were obtained from neurological patients undergoing a routine diagnostic lumbar puncture. The selection was coded and randomised from the Department's sample library. The CSF samples were centrifuged on receipt and stored at $4^{\circ} \mathrm{C}$. Analysis was performed within 1 week. Pooled CSF was obtained by taking an aliquot from routine samples. Ten pools of $10 \mathrm{ml}$ were obtained and stored at $-70^{\circ} \mathrm{C}$ until further analysis. The CSF analysis was in accordance with the MRC guidelines for handling of biological specimens and approved by the local Ethics Committee.

\subsection{Preparation of cell culture homogenate}

Primary cortical astrocytic, microglial and neuronal cell cultures were cultured and prepared from Wistar rats (1-2 days old, 7 days old and day 17 of ges- 
tation, respectively) as described Casley et al. (2002); Bolanos et al. (1995); Kingham and Pocock (2000). Astrocytes were cultured for 13 days, removed from the flask by trypsin digestion and seeded on to tissue culture plates at a density of $10^{6}$ cells/well (1500 cells/ $\mathrm{mm}^{2}$ ) Casley et al. (2002); Bolanos et al. (1995). Neurons were dissociated as above and seeded onto poly-ornithinecoated cell culture plates at a density of $2.5 \times 10^{6}$ cells/well $\left(3750\right.$ cells $\left./ \mathrm{mm}^{2}\right)$ Casley et al. (2002). Microglia cells were plated at $6 \times 10^{4}$ per $13-\mathrm{mm}$ coverslip Kingham and Pocock (2000). Culture medium was decanted, cells were washed with sample buffer, homogenised by sonication for $1 \mathrm{~min}$. on ice with a cover of argon gas and spun down at 20,000 g. The supernatant was stored at $-70^{\circ} \mathrm{C}$ until further analysis.

\subsection{Preparation of brain and spinal cord homogenate}

Snap-frozen blocks of brain and spinal cord tissue between 0.5 and $1 \mathrm{~g}$ wet weight, were cut and re-suspended at $1: 5 \mathrm{w} / \mathrm{v}$ in Tris-HCl buffer $(100 \mathrm{mM}$ Tris, pH 8.1 with $1 \%$ Triton X-100). Samples were homogenised on ice by sonication, triturated 3 times through 19 and 21 gauge needles and spun at $20,000 \mathrm{~g}$. Myelin protein was extracted by adding di-iso-propyl ether in the proportions of 1:5,000, centrifugation at $20,000 \mathrm{~g}$ and removal of the lipid layer. The protease inhibitor cocktail was added in a dilution of $1 / 100$ to supernatant. After dilution into aliquots of 1/1,1000, 1/5,000,1/10,000 and $1 / 100,000$ the samples were stored at $-70{ }^{\circ} \mathrm{C}$ until further analysis.

\subsection{Analytical procedure}

The microtitre plates were coated overnight with $100 \mu \mathrm{l}$ of capture antibody diluted $1 / 5000$ in $0.05 \mathrm{M}$ carbonate buffer, $\mathrm{pH}$ 9.5. The plate was washed with barbitone buffer containing $0.1 \%$ BSA and $0.05 \%$ Tween 20 (pH 8.9). The plate was blocked with $250 \mu \mathrm{l}$ of barbitone buffer containing $1 \%$ of BSA. After washing, $50 \mu \mathrm{l}$ of barbitone buffer, $6 \mathrm{mM}$ EDTA, 0.1\% BSA were added as sample diluent to each well. Fifty $\mu$ l of standard, control or CSF sample were then added in duplicate to the plate. The plate was incubated at room temperature (RT) for $1 \mathrm{~h}$. After washing, $100 \mu \mathrm{l}$ of the second antibody diluted $1 / 1000$ in barbitone buffer were added to each well and the plate was incubated for $1 \mathrm{~h}$ at RT. The microtitre plate was washed and HRP-labelled swine antirabbit antibody, diluted 1/1000, was added and incubated for $1 \mathrm{~h}$ at RT. After a final wash, $100 \mu \mathrm{l}$ of TMB substrate were added. The plate was incubated for $20 \mathrm{~min}$ at RT in the dark, the reaction was stopped by adding $50 \mu \mathrm{l} 1 \mathrm{M}$ $\mathrm{HCl}$ and the absorbance was read at $450 \mathrm{~nm}$ with $750 \mathrm{~nm}$ as the reference wavelength on a Wallac Victor2. 


\subsection{Statistical evaluation}

All statistical analyses and graphs were prepared using SAS software (version 8.2, SAS Institute, Inc., Cary, North Carolina, USA). Independent variables were compared using the non-parametric two-sample exact Wilcoxon rank-sum test or the unbalanced two-way ANOVA (general linear model) for more than two groups Cody and Smith (1997). In order to adjust for small sample size significant results were checked by comparison of proportions with the onetailed Fisher's exact test $(\alpha=0.05)$. The linear relationship between continuous variables was evaluated using the Spearman correlation coefficient $(\alpha=0.05)$. Linear regression analysis was performed using the least-squares method.

\section{Results}

\subsection{NfH phosphoforms}

\subsubsection{Selection of the capture antibody}

The standard curves for the $\mathrm{NfH}$ capture antibodies binding to phosphorylated $\mathrm{NfH}\left(\mathrm{NfH}^{S M I 34} \mathrm{NfH}^{S M I 35} \mathrm{NfH}^{S M I 310} \mathrm{NfH}^{\text {NE14 }}\right.$ ) and non-phosphorylated $\mathrm{NfH}\left(\mathrm{NfH}^{\text {SMI32 }} \mathrm{NfH}^{\text {SMI33 }} \mathrm{NfH}^{\text {SMI37 }} \mathrm{NfH}^{\text {SMI38 }} \mathrm{NfH}^{\text {SMI311 }}\right.$ ) are shown in Figure 1. The signal-to-noise ratio (absorbance value of the lowest standard divided by the absorbance of the blank reading) for each standard curve was calculated. The highest signal-to-noise ratio and widest analytical range were obtained for SMI35 as capture antibody. Therefore SMI35 was chosen as capture antibody for further development of the assay.

\subsection{Reproducibility of the standard curve}

Reproducibility of the standard curve was determined by expressing the absorbance obtained for each calibrant as a percentage of the absorbance of the highest standard. Twenty consecutive standard curves were normalised and the results averaged. The resulting regression for $\mathrm{NfH}^{S M I 35}$ is shown in Figure 2 . 


\subsection{Precision}

CSF samples (native and spiked with $\mathrm{NfH}$ ) were used to calculate the withinand between-batch precision and recovery.

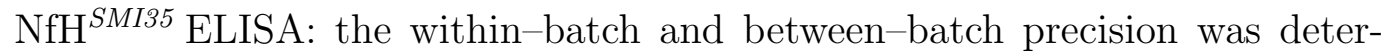
mined for high and low concentrations of 20 consecutive assays. The withinbatch precision was $5.6 \%$ for $2 \mathrm{ng} / \mathrm{ml}, 6.6 \%$ for $0.4 \mathrm{ng} / \mathrm{ml}, 19.8 \%$ for $0.2 \mathrm{ng} / \mathrm{ml}$, averaging to $10.6 \%$. The between-batch precision was $15 \%$ for $1.3 \mathrm{ng} / \mathrm{ml}, 31 \%$ for $0.16 \mathrm{ng} / \mathrm{ml}$, averaging to $23 \%$. The detection limit was $0.1 \mathrm{ng} / \mathrm{ml}$. The sensitivity was calculated as the mean +3 standard deviations of the blank signal from 20 assays. The sensitivity was $0.2 \mathrm{ng} / \mathrm{ml}$. The recovery of $\mathrm{NfH}^{\text {SMI35 }}$ in CSF was $121 \%$ for pool 1 and $116 \%$ for pool 2 , averaging at $119 \%$.

\subsection{Stability of $\mathrm{NfH}^{S M I 35}$}

Stability and susceptibility to proteolysis of $\mathrm{NfH}^{\text {SMI35 }}$ was tested at room temperature (RT), $4^{\circ} \mathrm{C}$ and $-70^{\circ} \mathrm{C}$. Five sets of pooled CSF samples were spiked with NfH. The CSF pools were then divided into aliquots of $1 \mathrm{ml}$ and frozen at $70^{\circ} \mathrm{C}$. The aliquots were thawed on day $0,2,5$ and 7 . After thawing the aliquots were stored at $4^{\circ} \mathrm{C}$ or RT until analysis. The measured absorbance for $\mathrm{NfH}$ of the samples was normalised to the absorbance of day 0 (Figure 3). There was a statistically significant difference between the groups $(\mathrm{F}(11,51)=2.56$, $\mathrm{p}<0.05)$. The subgroup analysis revealed that at RT a significant decrease of absorbance was present only between day 0 and day 7 (mean absorbance $=$ 1 versus $0.76, \mathrm{p}<0.01$ ), which could be prevented by adding proteinase inhibitors.

Stability of $\mathrm{NfH}$ to repetitive freezing and thawing was tested in 3 pools of CSF of which 2 aliquots were made. One aliquot was stored at $-70^{\circ} \mathrm{C}$, whilst the other underwent 5 freeze-thaw cycles prior to analysis. The absorbance of the latter was normalised to the former. The mean OD of the samples undergoing 5 freeze-thaw cycles was decreased by about $8 \%( \pm 13 \%)$, which remained within the range of the within-batch precision and did not reach statistical significance.

\subsection{Parallelism}

Parallelism between calibrant and CSF was studied by quantifying reciprocal dilutions of buffer spiked with $\mathrm{NfH}(10 \mathrm{ng} / \mathrm{ml}, 15 \mathrm{ng} / \mathrm{ml}$ and $20 \mathrm{ng} / \mathrm{ml})$ and native CSF samples with similar $\mathrm{NfH}^{\text {SMI35 }}$ concentrations $(11.7 \mathrm{ng} / \mathrm{ml}, 17.3$ 
$\mathrm{ng} / \mathrm{ml}$ and $22.4 \mathrm{ng} / \mathrm{ml}$ ). The obtained absorbance for each series of dilutions was normalised to the highest value within this series (100\%). Because of the vertical displacement the top value is not shown. The parallel relationship is demonstrated in Figure 4. This suggested the absence of endogenous binding between CSF $\mathrm{NfH}^{\text {SMI35 }}$ and other CSF substrates.

\subsection{Aggregate formation of purified neurofilaments}

The bovine neurofilament heavy chain aggregated in spiked CSF at $4^{\circ} \mathrm{C}$, $-20^{\circ} \mathrm{C}$ and $-70^{\circ} \mathrm{C}$. Eight pooled samples of spiked CSF were measured without and after sonication. Samples were sonicated for $1 \mathrm{~min}$ on ice with a cover of argon gas. Aggregates could be broken up by sonication (Figure $5 \mathrm{~A}$ ). The measured amount of $\mathrm{NfH}$ for frozen samples after sonication was about twice as high if compared to samples which were not sonicated. The error-bars (SD) between the groups overlapped suggesting the presence of aggregates at all temperatures. Spontaneous disassembly of neurofilament protein aggregates was tested at RT and $4^{\circ} \mathrm{C}$. In spiked CSF samples spontaneous disassembly was observed about 3 days after thawing (Figure $5 \mathrm{~B}$ ). The large error-bars indicate considerable heterogeneity over this period, probably caused by simultaneous presence of aggregate dissolution and proteolysis.

\subsection{Stability of reagents}

No problems were found with stability of antibodies. To minimise any problems with cumulative contamination, the antibodies were stored in $100 \mu \mathrm{l}$ aliquots and used within 4 weeks. All buffers were stored at $4^{\circ} \mathrm{C}$ and used within 1 week.

\subsection{Cross reactivity}

Measuring double dilutions of a known amount of protein, the cross-reactivity of the $\mathrm{NfH}^{\text {SMI35 }}$ ELISA with HPLC purified bovine NfM was $7.8 \%$, with bovine NfL $6.5 \%$ and with bovine GFAP $0.06 \%$. There was no cross-reactivity with red-cells, white cells or haemolysed blood. 


\subsection{Cell-culture and human CNS tissue homogenate}

About 25 to 57 -fold higher $\mathrm{NfH}^{\text {SMI35 }}$ levels were found in neuronal (0.68 \pm 0.04 $\mathrm{ng} / \mathrm{mg}$ protein; mean $\pm \mathrm{SD})$ cell cultures in contrast to microglial $(0.027 \pm 0.028$ $\mathrm{ng} / \mathrm{mg}$ protein) or astrocytic $(0.012 \pm .01 \mathrm{ng} / \mathrm{mg}$ protein) cell cultures (Figure $6 \mathrm{~A})$.

The highest $\mathrm{NfH}^{S M I 35}$ levels were found in tissue homogenates from human spinal cord white matter (WM) $(213.6 \pm 187.5 \mathrm{ng} / \mathrm{mg}$ protein), followed by cortical WM (52.3 \pm 32.9$)$ and cortical grey matter (GM, $12.47 \pm 11.5 \mathrm{ng} / \mathrm{mg}$ protein, Figure $6 \mathrm{~B})$.

\subsection{Reference population}

Cerebrospinal fluid samples from 463 patients were assayed for $\mathrm{NfH}^{\text {SMI35 }}$. The distribution of the $\mathrm{NfH}^{\text {SMI35 }}$ CSF levels was non-Gaussian (Figure $7 \mathrm{~A}$ ). In order to obtain a biologically representative population the top 10\% (NfH $>1.119 \mathrm{ng} / \mathrm{ml}$ ) have been removed, leaving 416 patients. The mean age of the reference population so determined was $42.4 \pm 17.9$ years, with a median of 41.9 (IQR 31.2-55.8) years. There was no correlation between CSF $\mathrm{NfH}^{\text {SMI35 }}$ and age $(\mathrm{R}=0.065, \mathrm{p}=0.2)$. Fifty-eight percent $(242 / 416)$ were female, $39.9 \%(166 / 416)$ male, and in $8(1.9 \%)$ patients no gender information was available. There was no significant difference in $\mathrm{CSF} \mathrm{NfH}^{S M I 35}$ levels between the genders.

The relative frequency distribution of the reference-population was then subjected to non-parametric definition of the upper reference value of the 95 percentile Solberg (1994). The upper reference value corresponds to $0.73 \mathrm{ng} / \mathrm{ml}$ (Figure $7 \mathrm{~A}$, reference line). The mean value of $\mathrm{CSF} \mathrm{NfH}^{S M I 35}$ was $0.25 \pm 0.23$ $\mathrm{ng} / \mathrm{ml}$ with a median of $0.21 \mathrm{ng} / \mathrm{ml}$ and an interquartile range of 0.07 to 0.35 $\mathrm{ng} / \mathrm{ml}$. The data were skewed towards zero by 1.33 . The kurtosis was 2.15 indicating a high slim peak with more values in the tails than expected for a Gaussian distribution. This was due to $18 \%$ of samples with non detectable CSF NfH ${ }^{\text {SMI35 }}$ levels.

\subsection{CSF NfH $\mathrm{HIIS}^{\text {in }}$ neurological disorders}

After determination of the upper reference limit for the $\mathrm{NfH}^{S M I 35}$ assay, a second population of patients was selected according to the clinical diagnosis: Nine patients had cluster headache (HD) with no other evidence of organic

pathology in the central nervous system. Two had a space-occupying lesion 
(SO), one due to a cyst of the right lateral ventricle and one to a non Hodgkin lymphoma. Three had amyotrophic lateral sclerosis (ALS), 3 a lumbar disc prolapse (DP), 36 laboratory supported (isolated intrathecal IgG synthesis) evidence for demyelinating disease (DM), 14 had Guillain-Barré syndrome (GBS) and 5 had a subarachnoid haemorrhage (SAH). All CSF was taken by routine lumbar puncture, except for SAH where the CSF was taken for routine infectious screening 2 days after placement of an extra-ventricular drain. The values for the SAH cases therefore represents ventricular CSF.

Because of the small patient numbers statistical significance was checked on a categorical level by the Fisher's exact test comparing proportions of patients with CSF $\mathrm{NfH}^{S M I 35}$ levels above the previously calculated upper reference value (cut-off) of $0.73 \mathrm{ng} / \mathrm{ml}$. A significantly higher number of patients with SAH had CSF $\mathrm{NfH}^{\text {SMI35 }}$ levels above the cut-off when compared to HD $(\mathrm{p}<0.001)$ or DM $(\mathrm{p}<0.001)$. A significantly higher number of patients with SO had CSF NfH ${ }^{\text {SMIS5 }}$ levels above the cut-off when compared to HD $(\mathrm{p}<0.05)$ or DM $(\mathrm{p}<0.01)$ and a significantly higher number of patients with ALS or DP had CSF NfH ${ }^{S M I 35}$ levels above the cut-off when compared to DM $(\mathrm{p}<0.05$, $\mathrm{p}<0.05$, respectively).

\section{Discussion}

The novel ELISA method presented here is straightforward and based entirely on commercially available antibodies. The $\mathrm{NfH}^{S M I 35}$ protein was stable over a 1 -week period if samples were stored at $4^{\circ} \mathrm{C}$. For longer storage either freezing at or below $-20^{\circ} \mathrm{C}$ or addition of a protease inhibitor cocktail is recommended. The detection limit of the $\mathrm{NfH}^{S M I 35}$ ELISA was $0.01 \mathrm{ng} / \mathrm{ml}$ and the sensitivity $0.02 \mathrm{ng} / \mathrm{ml}$ with a reasonable precision profile $(5.6 \%-31 \%)$.

The upper reference value of $0.73 \mathrm{ng} / \mathrm{ml} \mathrm{NfH}^{S M I 35}$ has to be regarded as conservative. It applies to a hospital population of a tertiary referral centre biased towards neurological diseases. In a general hospital population a more suitable upper reference value would need to be established and is likely to be lower.

Because this ELISA is the first one reported to measure $\mathrm{NfH}^{S M I 35}$ in human CSF, no cross-validation with another NfH assay was possible. An ELISA for measuring $\mathrm{NfH}$ in brain homogenate has been reported, but the reproducibility was not rigorous Hashimoto et al. (1999). An ELISA for quantifying the light chain (NfL) has already been developed Rosengren et al. (1996). A stability profile of NfL in CSF was not presented, but the authors mentioned the susceptibility of NfL to proteolysis and refer to previous work Schlaepfer et al. (1985); Wang et al. (1992). The strategy chosen by Rosengren et al. to prevent protease digestion of NfL was to snap-freeze samples directly after 
lumbar puncture and store at $-70^{\circ} \mathrm{C}$ Rosengren et al. (1996). Samples were only thawed directly prior to analysis Rosengren et al. (1996).

Repeated freeze-thaw cycles $(\mathrm{n}=5)$ did not significantly affect $\mathrm{NfH}^{\text {SMI35 }}$ stability in native CSF. However, for CSF spiked with HPLC-purified bovine NfH it was shown that freezing caused the formation of aggregates. Once aggregates had formed they could be broken up by sonication. The finding of increasing temperature and time-dependent $\mathrm{NfH}^{\text {SMI35 }}$ levels after aggregate formation suggests the presence of enzymatic breakdown mechanisms.

Rosengren et al. (1996) report a cross-reactivity of their assay with $\mathrm{NfH}$ of 15\%. The amount of CSF-NfH contributing to the CSF-NfL levels in a series of studies from this group Rosengren et al. (1996); Brisby et al. (1999); Rosengren et al. (1999); Holmberg et al. (1998); Lycke et al. (1998) is not known, but could be considerable if stability of NfL should be an issue Schlaepfer et al. (1985); Wang et al. (1992). In comparison the cross-reactivity of the present

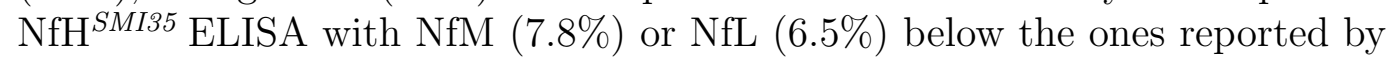
Rosengren and colleagues. This might be explained by the use of a capture antibody against an epitope on the $\mathrm{C}$-terminal $\mathrm{NfH}$ tail domain which is unlikely to share homology with NfL or NfM. The possibility of contamination of the HPLC-purified bovine proteins used in this study by some residual NfH should also be taken into account. This hypothesis should be addressed by the use of recombinant $\mathrm{Nf}$ proteins in future work.

The $\mathrm{NfH}^{\text {SMI35 }}$ ELISA is highly specific for $\mathrm{NfH}^{\text {SMI35 }}$ present in primary neuronal cell cultures, compared to primary astrocytic or microglial cultures. It is of note that under normal conditions the perikaryal content of phosphorylated NfH in neurons is much lower than in axons Fuchs and Cleveland (1998); Miller et al. (2002). Therefore it was not surprising that the highest levels of $\mathrm{NfH}^{\text {SMI35 }}$ were measured in homogenate from spinal cord white matter, where axons are packed with high density. Whilst the ELISA has been optimised for the measurement of $\mathrm{NfH}^{S M I 35}$ from CSF, we found that the range of the assay permitted considerable extension of the standard curve, which was more suitable for measurement of $\mathrm{NfH}^{S M I 35}$ from CNS tissue homogenate.

An important caveat of the present $\mathrm{NfH}^{S M I 35}$ ELISA is that the phosphorylation and dephosphorylation of $\mathrm{NfH}$ is a highly dynamic process Nixon and Sihag (1991) likely to influence the levels of CSF $\mathrm{NfH}^{S M I 35}$. This particularly applies to pathological conditions of the central nervous system Lee et al. (1988); Martin et al. (1990); Fuchs and Cleveland (1998); Miller et al. (2002). It would be desirable to develop ELISA techniques which would allow quantification of a profile of $\mathrm{NfH}$ phosphoforms. Unfortunately, none of the capture antibodies against non-phosphorylated NfH epitopes in non-phosphorylated NfH (SMI32, SMI37, SMI38, SMI311) or against a non-phosphorylated epitope in phosphorylated NfH (SMI33) provided a satisfactory sensitivity with 
the present detector system.

In neurological diseases the highest levels of $\mathrm{CSF} \mathrm{NfH}^{S M I 35}$ were observed in the ventricular CSF of patients with SAH, followed by lumbar CSF from patients with amyotrophic lateral sclerosis, space-occupying lesions and disc prolapses. The comparison of ventricular with lumbar CSF has to be done with caution as nothing is known about the NfH concentration across the CSF

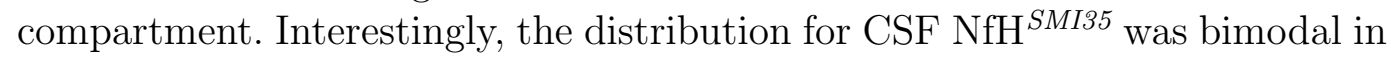
GBS patients. This finding warrants further investigation.

In order to accommodate the emerging need to differentiate between NfH phosphoforms with immunological methods a new nomenclature has been proposed in Table 1. This nomenclature is based on the name of the capture antibody and will facilitate the comparison between immunocytochemistry, immunoblot and ELISA using these antibodies. This nomenclature also takes into account that the exact binding epitopes are not always known and that epitope recognition might be influenced by post-translational modifications. The proposed nomenclature can easily be expanded to incorporate other capture antibodies which might help to distinguish different $\mathrm{NfH}$ phosphoforms.

\section{Acknowledgements}

This study was supported by the Multiple Sclerosis Society of Great Britain and Northern Ireland and the BR Kirk Fund of the Institute of Neurology. We are grateful to Dr L Canevari, Dr J Pocock, Dr V Steward, Dr C Casley, Mrs A Helsegrave for providing cell-culture material, Ms D Grant for technical and Ms J Alsop for secretarial assistance.

\section{References}

Bolanos, J., Heales, S., Land, J., Clark, J., 1995. Effect of peroxynitrite on the mitochondrial respiratory chain: differential susceptibility of neurones and astrocytes in primary culture. J Neurochem 64, 1965-1972.

Brisby, H., Olmarker, K., Rosengren, L., Cederlund, C., Rydevik, B., 1999. Markers of nerve tissue injury in the cerebrospinal fluid in patients with lumbar disc herniation and sciatica. Spine 24, 742-746.

Casley, C., Canevari, L., Land, J., Clark, J., Sharpe, M., 2002. Beta-amyloid inhibits integrated mitochondrial respiration and key enzyme activities. J Neurochem 80, 91-100.

Ching, G., Liem, R., 1998. Roles of head and tail domains in alpha-internexin's self- assembly and coassembly with the neurofilament triplet proteins. J Cell Science 111, 321-333. 
Cody, P., Smith, J., 1997. Applied Statistics and the SAS Programming Language, 4th Edition. Prentice-Hall, Upper Saddle River, New Jersey 07458.

Fuchs, E., Cleveland, D., 1998. A structural scaffolding of intermediate filaments in health and disease. Science 279, 514-519.

Goldstein, M., Sternberger, N., Sternberger, L., 1987. Phosphorylation protects neurofilaments against proteolysis. J Neuroimmunol 14, 149-160.

Hashimoto, R., Nakamura, Y., Ichiro, T., et al., 1999. Quantitative analysis of neurofilament proteins in Alzheimer's brain by enzyme linked immunosorbent assay system. Psychiat and Clin Neurosci 53, 587-591.

Holmberg, B., Rosengren, L., Karlsson, J., Johnels, B., 1998. Increased cerebrospinal fluid levels of neurofilament protein in progressive supranuclear palsy and multiple-system atrophy compared with Parkinson's disease. Movement Disorders 13, 70-77.

Kingham, P., Pocock, J., 2000. Microglial apoptosis induced by chromogranin $\mathrm{A}$ is mediated by mitochondrial depolarisation and the permeability transition but not by cytochrome c release. J Neurochem 74, 1452-1462.

Lee, V., Otvos, L., Schmidt, M., Trojanowski, J., 1988. Alzheimer-disease tangles share immunological similarities with multiphosphorylation repeats in the 2 large neurofilament proteins. Proceedings National Academy Sciences United States America 85, 7384-7388.

Lees, J., Shneidman, P., Skuntz, S., Carden, M., Lazzarini, R., 1988. The structure and organization of the human heavy neurofilament subunit (NFH) and the gene encoding it. EMBO1988 7, 1947-1955.

Lycke, J., Karlsson, J., Andersen, O., Rosengren, L., 1998. Neurofilament protein in cerebrospinal fluid: a potential marker of activity in multiple sclerosis. J Neurol Neurosurg Psychiatry 64, 402-404.

Martin, J., Mather, K., Swash, M., Garofalo, O., Dale, G., Leigh, P., Anderton, B., 1990. Spinal cord trauma in man: studies of phosphorylated neurofilament and ubiquitin expression. Brain 113, 1553-1562.

Miller, C., Ackerley, S., Brownlees, J., Grierson, A., Jacobsen, N., Thornhill, P., 2002. Axonal transport of neurofilaments in normal and disease states. Cell Mol Life Sci 59, 323-330.

Nixon, R., Sihag, R., 1991. Neurofilament phosphorylation - a new look at regulation and function. Trends Neurosciences 14, 501-506.

Rosengren, L., Karlsson, J., Karlsson, J., Persson, L., Wikkelso, C., 1996. Patients with amyotrophic lateral sclerosis and other neurodegenerative diseases have increased levels of neurofilament protein in CSF. J Neurochem 67, 2013-2018.

Rosengren, L., Karlsson, J., et al., 1999. Neurofilaments protein levels in CSF are increased in dementia. Neurology 52, 1090-1093.

Schlaepfer, W., Lee, C., Lee, V., Zimmerman, U., 1985. An immunoblot study of neurofilament degradation in situ and during calcium-activated proteolysis. J Neurochem 44, 502-509.

Solberg, H., 1994. Tietz Textbook of Clinical Chemistry, 2nd Edition. WB Saunders Company, Philadelphia, Pensylvania 19106, Ch. Establishing and 
Use of Reference Values, pp. 454-484.

Sternberger, L. (Ed.), 1986. Immunocytochemistry, 3rd Edition. John Wiley, New York.

Sternberger, L., Harwell, L., Sternberger, N., 1982. Neurotype: Regional individuality in rat brain detected by immunocytochemistry with monoclonal antibodies. Proc Natl Acad Sci USA 79, 1326-1330.

Sternberger, L., Sternberger, N., 1983. Monoclonal antibodies distinguish phosphorylated and non phosphorylated forms of neurofilaments in situ. Proc Natl Acad Sci USA 82, 6126-6130.

Trapp, B., Peterson, J., et al., 1998. Axonal transection in the lesions of multiple sclerosis. N Eng J Med 338, 278-285.

Wang, S., Lees, G., Rosengren, L., Karlsson, J., Hamberger, A., Haglid, K., 1992. Proteolysis of filament proteins in glial and neuronal cells after in vivo stimulation of hippocampal NMDA receptors. Neurochem Res 17, 10051009 . 


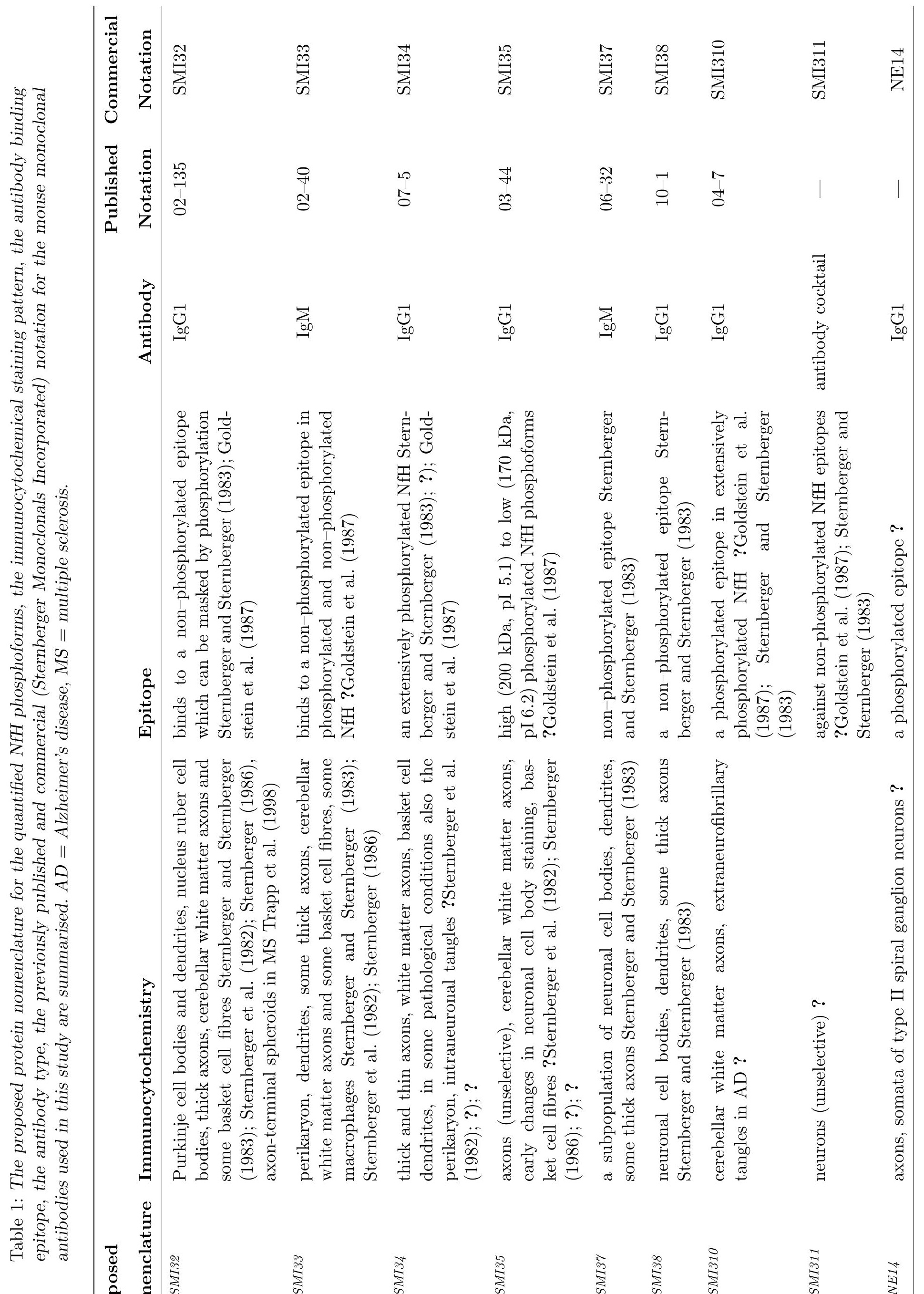




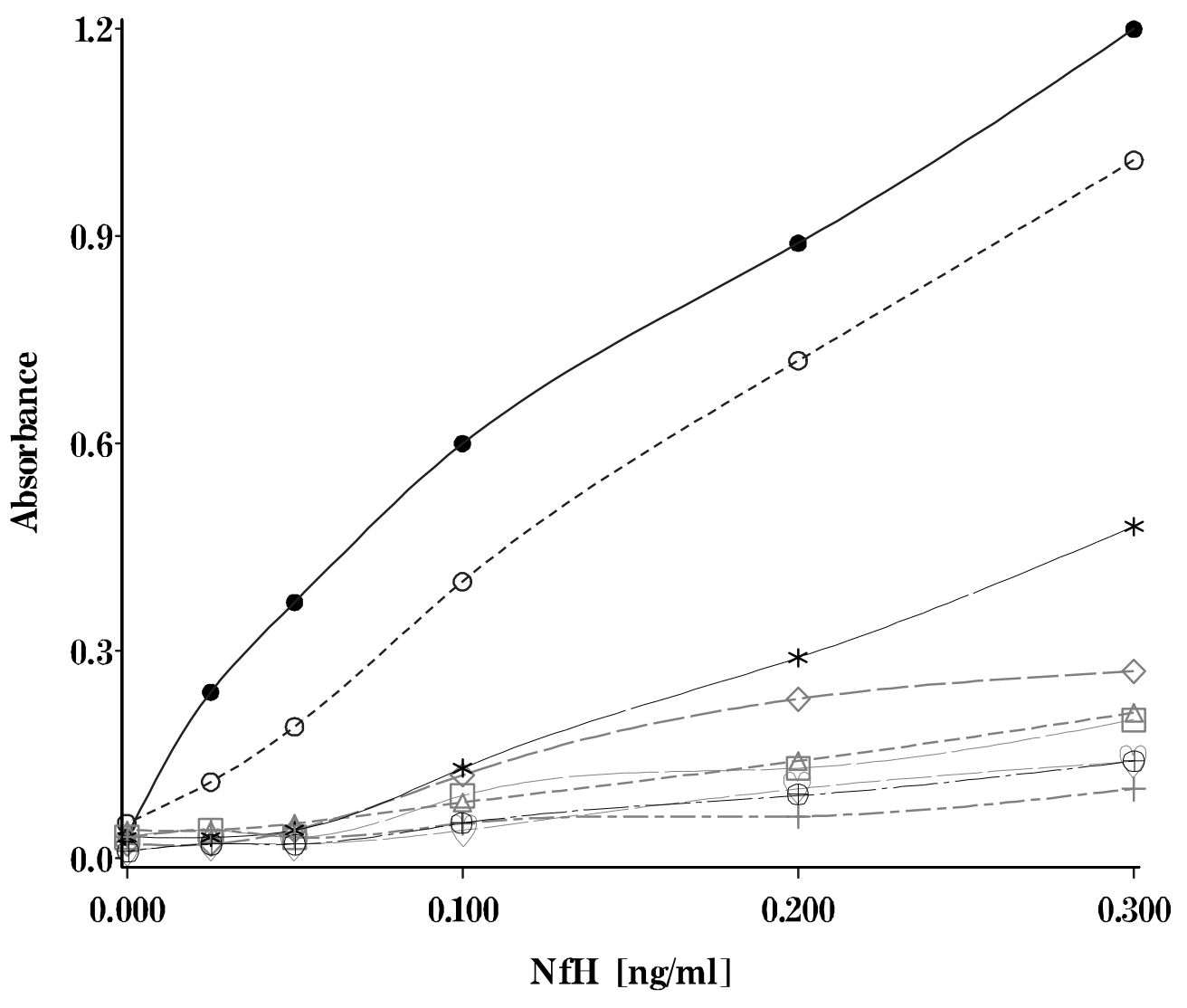

Figure 1. NfH phosphoforms. The standard curves for different capture antibodies against phosphorylated $\left(\mathrm{NfH}^{S M I 34}={ }^{\mathrm{S}}, \mathrm{NfH}^{S M I 35}=\bullet, \mathrm{NfH}^{S M I 310}={ }^{*}, \mathrm{NfH}^{\mathrm{NE14}}=\right.$ $\oplus$, black lines) and non-phosphorylated epitopes $\left(\mathrm{NfH}^{\text {SMI32 }}=\triangle, \mathrm{NfH}^{\text {SMI33 }}=\diamond\right.$, $\mathrm{NfH}^{\text {SMI37 }}=\mathrm{Q}, \mathrm{NfH}^{\text {SMI38 }}=\square, \mathrm{NfH}^{\text {SMI311 }}=+$, grey lines $)$ are shown. 


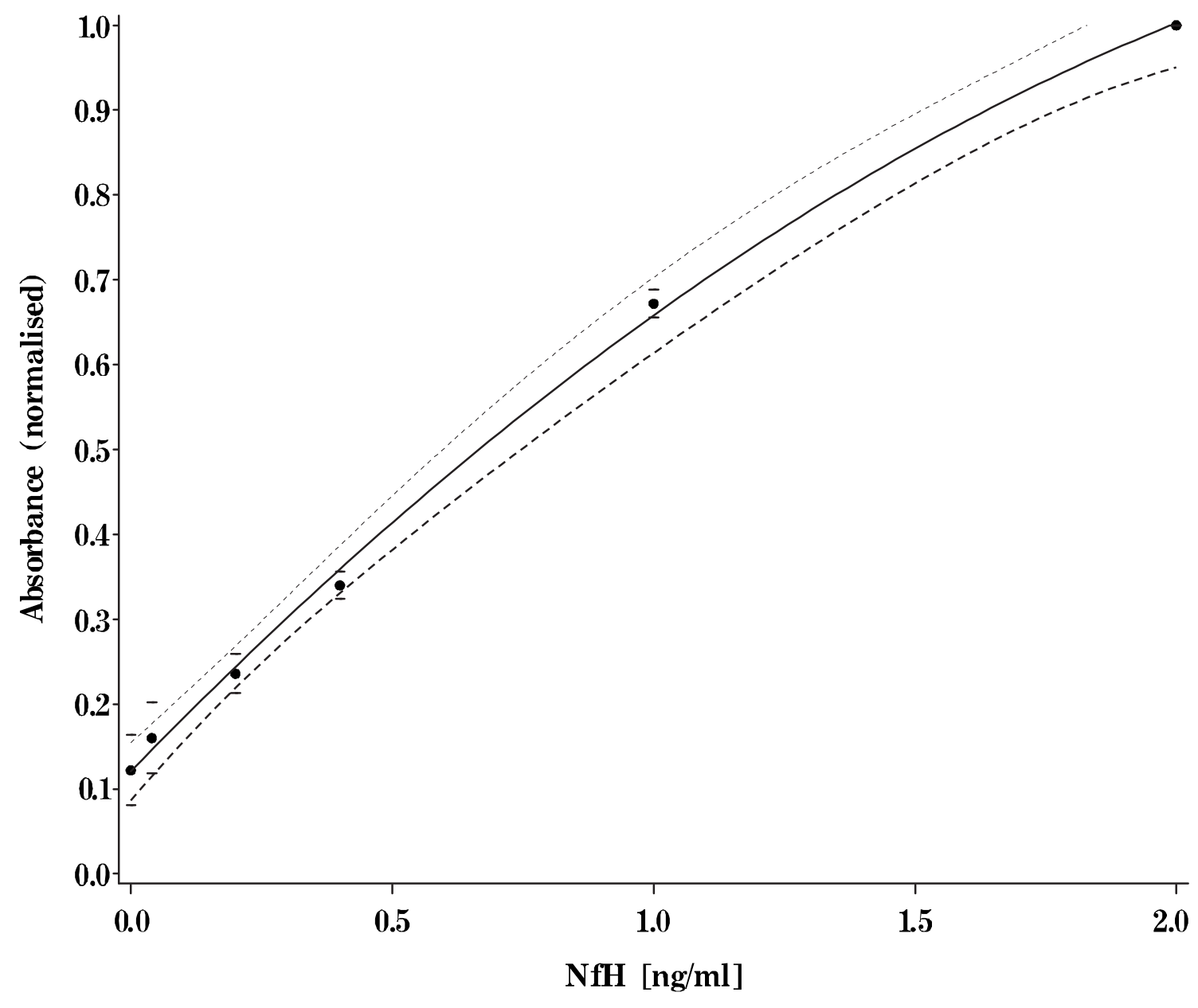

Figure 2. Standard-curve for the NfH $\mathrm{H}^{S M I 35}$ assay. Reproducibility of twenty consecutive normalised calibration lines. The graph shows the mean values (dots) \pm standard deviation (bars), quadratic regression line, $5 \%$ and $95 \%$ confidence interval curves. 


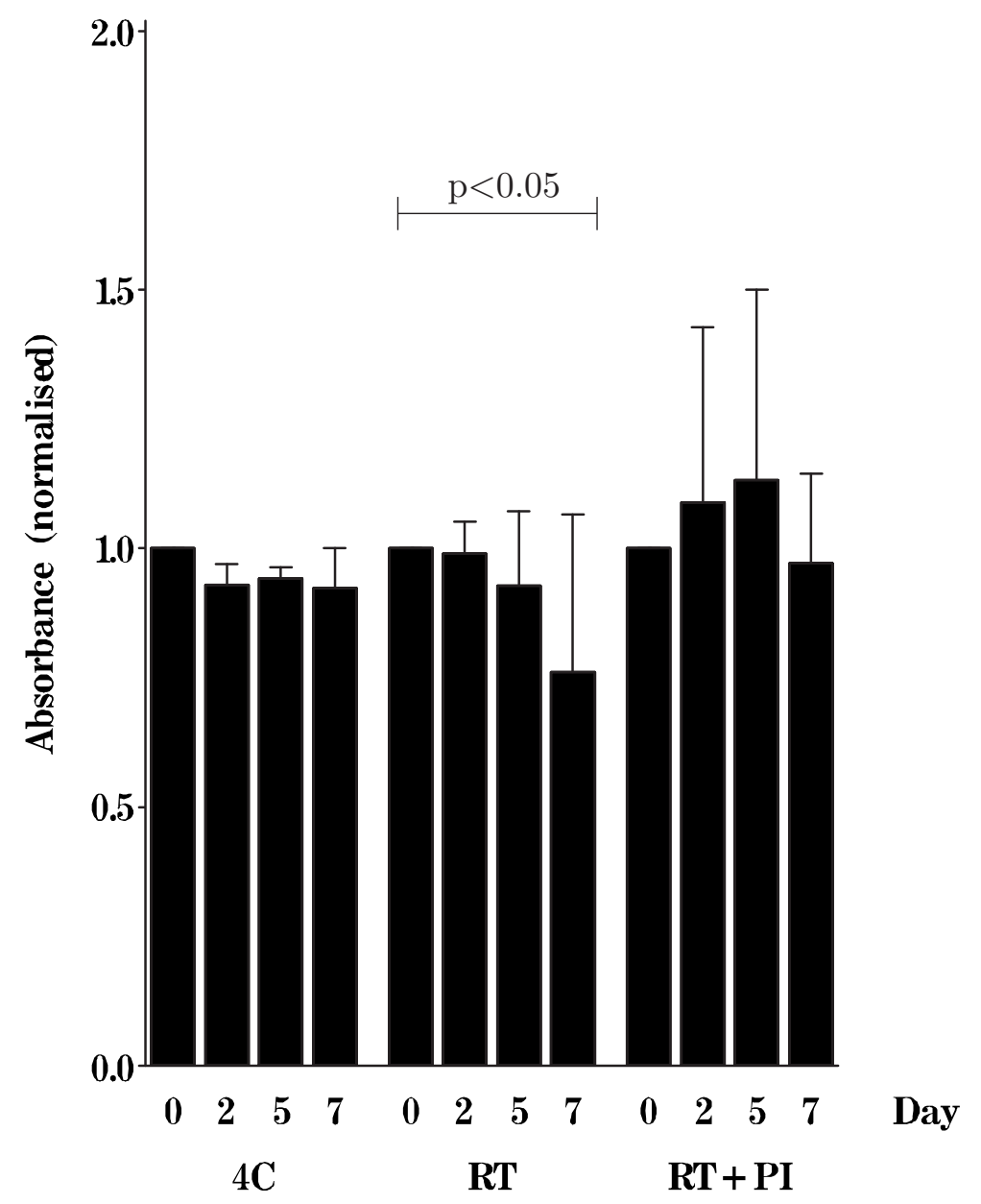

Figure 3. Stability profile of $\mathrm{NfH}^{S M I 35}$ in native CSF $(n=6)$ over 7 days at room temperature $(R T)$ or $4^{\circ} \mathrm{C}$ in percentage absorbance compared to a sample stored at $-70^{\circ} \mathrm{C}$. PI indicates samples with added protease inhibitors stored at $R T$. The mean $\pm S D$ are shown. 


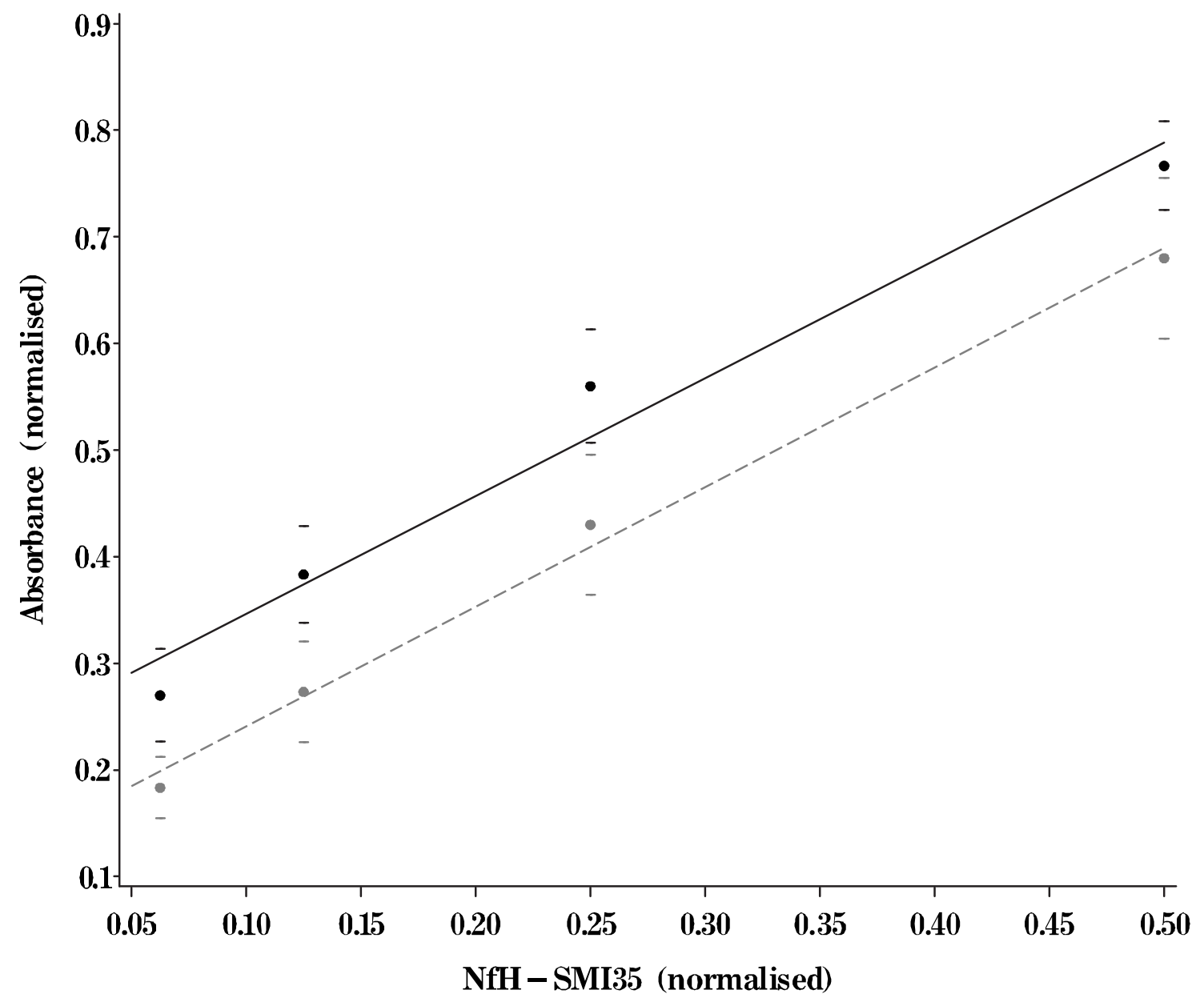

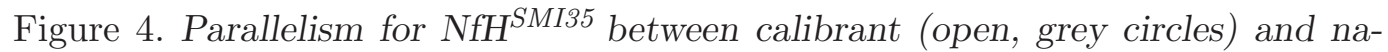
tive CSF (closed, black circles). The linear regression, mean (circles) and standard deviation (horizontal bars) are shown. 
A

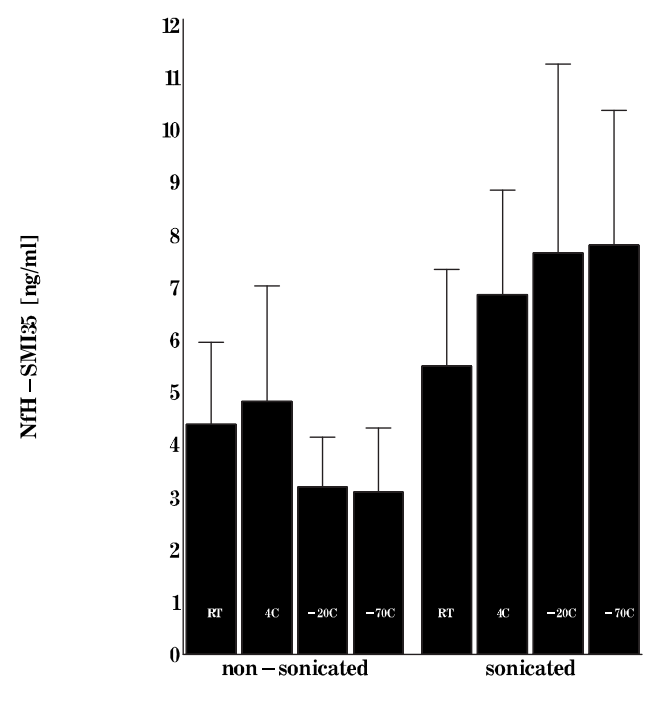

B

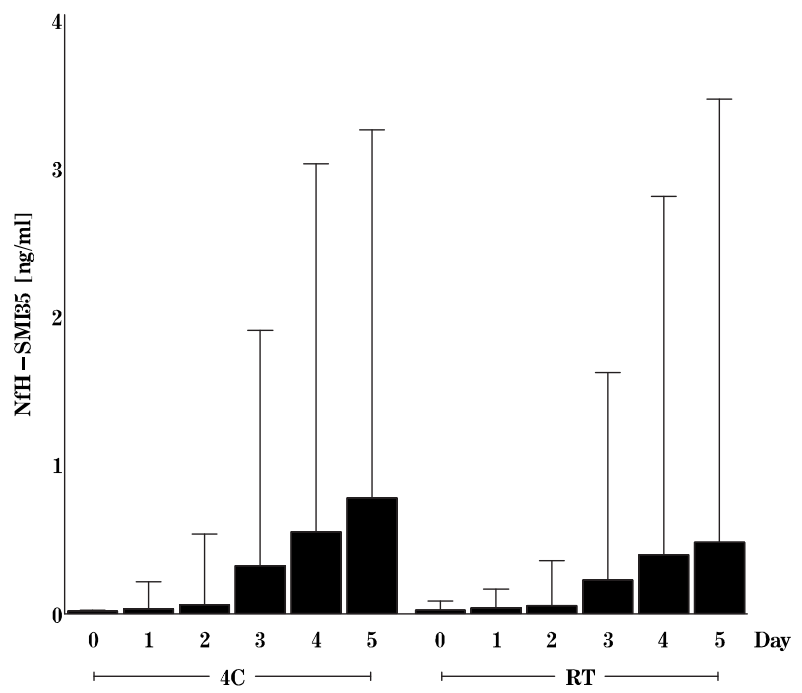

Figure 5. (A) $\mathrm{NfH}^{S M I 35}$ aggregate formation in spiked CSF (mean, SD). Non-sonicated (left) and sonicated (right) samples are shown for 7-day storage at room temperature $(R T), 4^{\circ} \mathrm{C},-20^{\circ} \mathrm{C}$ and $-70^{\circ} \mathrm{C}$. (B) Spontaneous disassembly

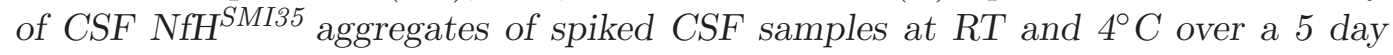
observation period. The mean $\pm S D$ are shown. 


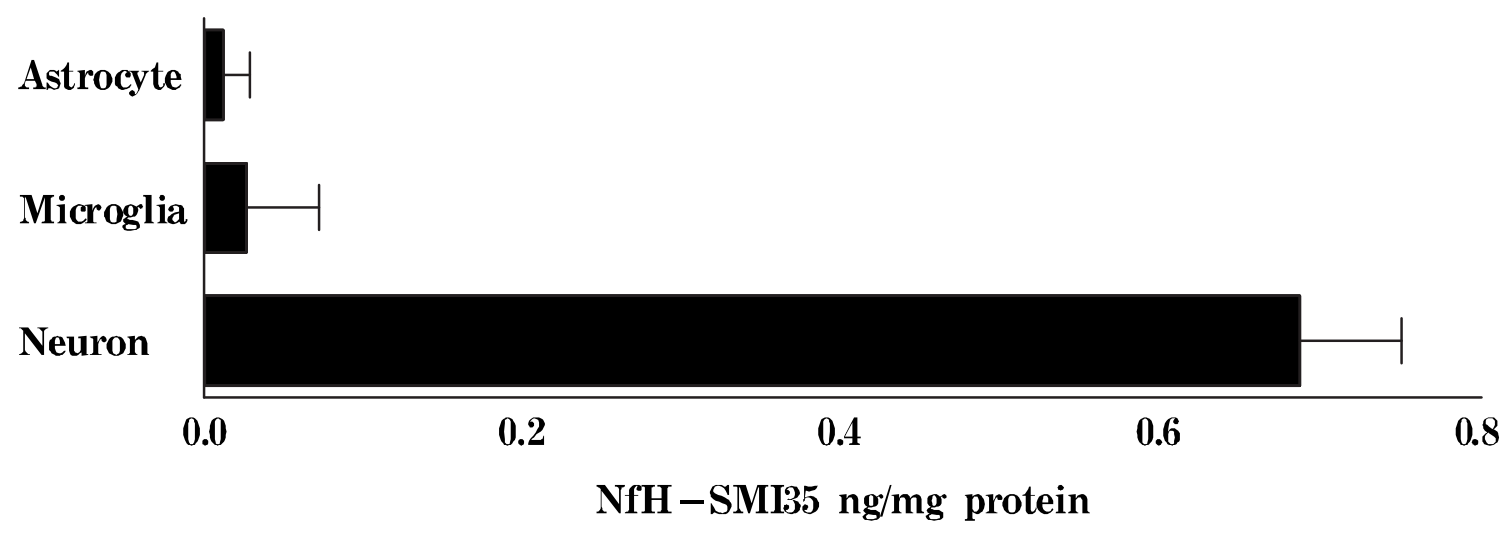

B

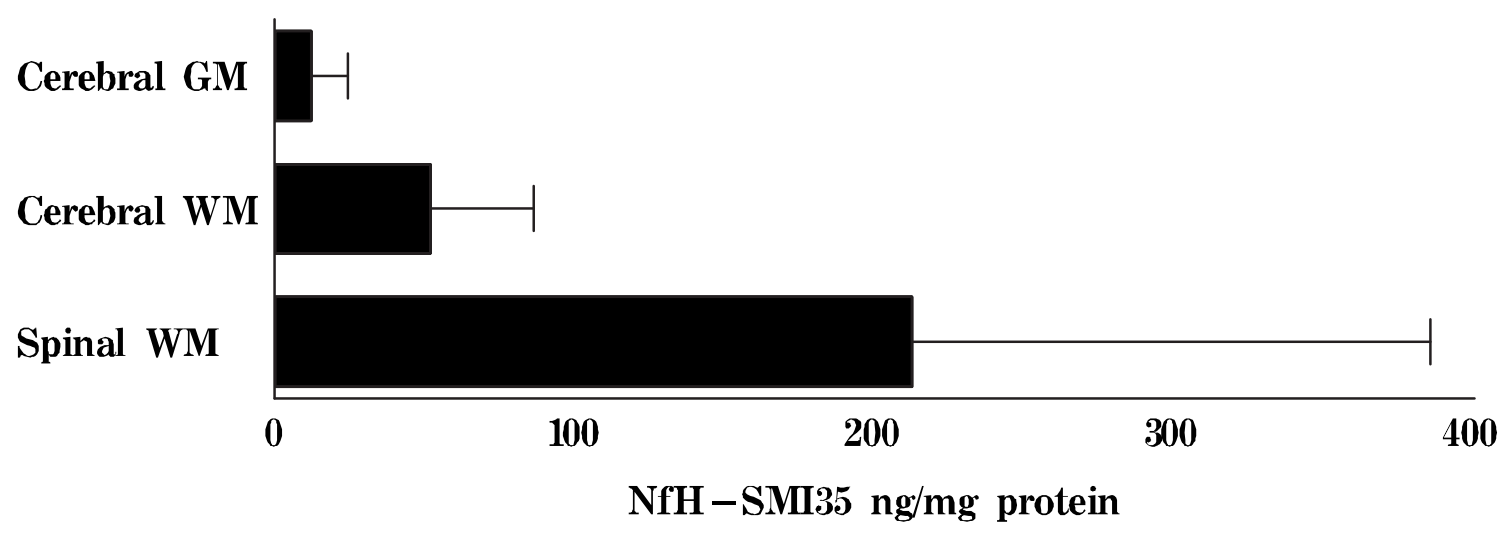

Figure 6. Levels of $\mathrm{NfH}^{S M I 35} \mathrm{ng} / \mathrm{mg}$ protein in (A) homogenised neurons, astrocytes and microglia, $(B)$ in tissue homogenate from cerebral grey matter (GM), white matter $(W M)$ and spinal cord white matter (mean $\pm S D)$. 


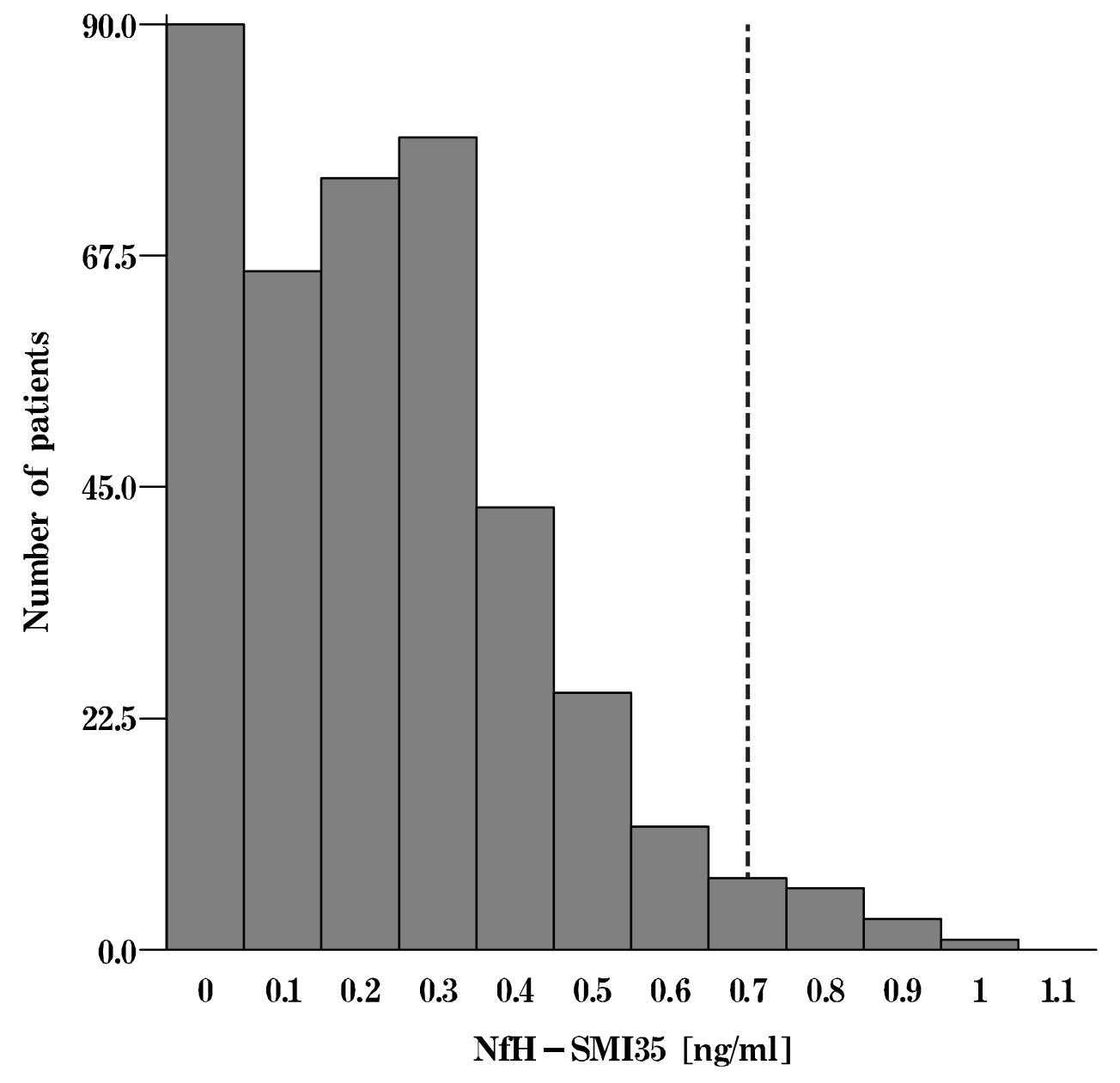

Figure 7. Frequency histogram for the reference population for CSF $\mathrm{NfH}^{\text {SMI35 }}$ ( $\mathrm{n}=416$ ), the upper reference value of $0.73 \mathrm{ng} / \mathrm{ml}$ is shown (dotted line). 


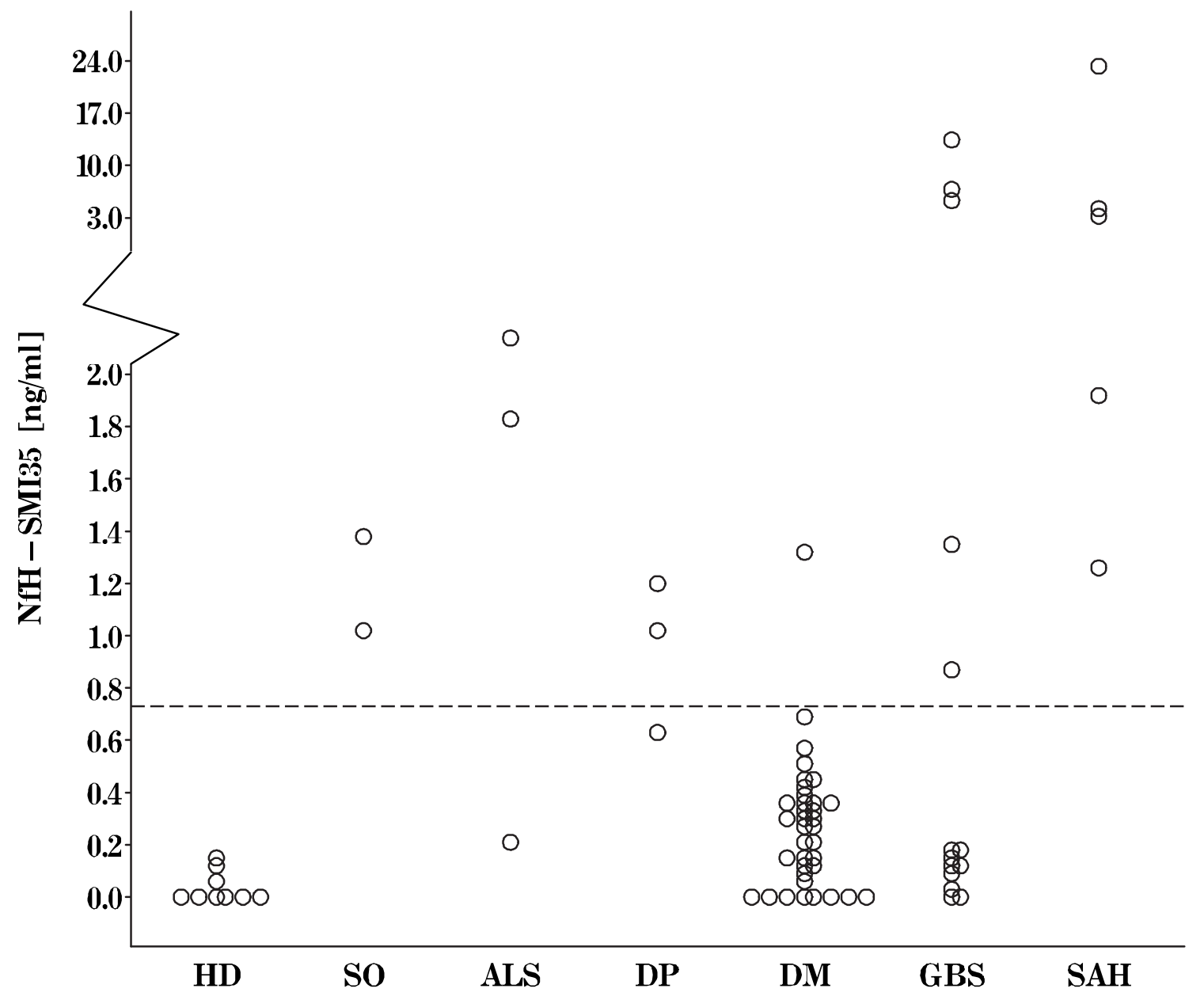

Figure 8. Scatter plot of CSF NfH ${ }^{S M I 35}$ levels in patients with cluster headache $(H D)$, space-occupying lesions (SO), amyotrophic lateral sclerosis (ALS), disc prolapse (DP, demyelinating disease (DM), Guillain-Barré syndrome (GBS) and subarachnoid haemorrhage $(S A H)$. The horizontal reference line (dotted) represents the cut-off $(0.73 \mathrm{ng} / \mathrm{ml})$ derived from the reference population, the $y$-axis is split at 2 $n g / \mathrm{ml}$. 